\title{
Innate Immunity and Human Milk MicroRNAs Content: A New Perspective for Premature Newborns
}

\author{
Erika Cione, ${ }^{1,}$ Maria Lucente, ${ }^{2}$ Luca Gallelli, ${ }^{3}$ Giovambattista De Sarro, ${ }^{3}$ Filippo Luciani, ${ }^{4}$ and Maria \\ Cristina Caroleo ${ }^{1}$ \\ ${ }^{1}$ Department of Pharmacy and Health and Nutritional Sciences, University of Calabria, GalaScreen Laboratories, Rende, Italy \\ ${ }^{2}$ Neonatology Unit of Annunziata Hospital, Cosenza, Italy \\ ${ }^{3}$ Department of Health Science, School of Medicine, University of Catanzaro and Operative Unit of Clinical Pharmacology and Pharmacovigilance, MaterDomini Hospital, \\ Catanzaro, Italy \\ ${ }^{4}$ Infectious Disease Unit of Annunziata Hospital, Cosenza, Italy \\ "Corresponding author: Erika Cione, PharmD, PhD, Department of Pharmacy and Health and Nutritional Sciences, University of Calabria-Italy, Via A. Savinio - 87036 Rende (CS). \\ Tel: +98-4493193, E-mail: erika.cione@unical.it
}

Received 2016 October 25; Revised 2017 January 28; Accepted 2017 February 03.

\begin{abstract}
Context: The premature newborns are prone to develop both early onset and late onset neonatal sepsis. The major causes of this phenomenon rely on the immaturity of the immune system, which has reduced capability to respond adequately to pathogens.

Evidence Acquisition: Titles and abstracts of previous papers were scanned before reading the full-text, in order to retrieve appropriate information. The databases used for searching were PubMed, Cochrane, and Embase for articles published before 1st of July, 2016. Secondary search for articles cited in reference lists were identified by the primary search. This review focused on neonatal sepsis incidence and the associated immune response with regards to microRNAs of human milk as a new microelement that enables regulation of innate immunity functions.

Results: Since human milk is a valuable source of microRNAs, a better understanding of its content will open a new therapeutic avenue for the clinical management of infectious diseases affecting premature newborns. The variation in miRNAs quantity in human milk needs to be considered. Mother's milk can have different amounts of miRNAs and the identification of a microMilk batch richer of miRNAs can be a nutrition intervention method for modulating innate immunity in clinical management of premature newborns.

Conclusions: Routine translation of the microMilk concept for neonatal intensive care unit (NICU), in the management of premature newborns could be a way of defending premature newborns and Very Low Birth Weight (VLBW) infants from both early and late sepsis.
\end{abstract}

Keywords: Premature Newborn, Human Milk, Immune System, Sepsis, MicroRNA

\section{Context}

Premature newborns are prone to develop infection as shown by world statistics reporting that neonatal infections cause about $35 \%$ of the estimated 4 million neonatal deaths, annually $(1,2)$. Neonates, who survive sepsis, have an increased risk of prolonged hospitalization, broncopulmonary dysplasia, and unfavorable neurodevelopment $(3,4)$. The prevalence of neonatal sepsis is inversely correlated with gestational age and birth weight (5), and it is related to the physiological immaturity of the newborns immune system (6). In the gestational room, the fetus develops its immune system in a sterile and safe milieu, thus it misses the antigenic experience; in addition, the fetus's immune system coexists with the immune system of the mother. Therefore, after birth the newborn is bare to the microbial "adverse world" and should defend itself immediately. In the first three months of life, neonate's immunologic competence progresses rapidly as the cells of adaptive immunity mature acquiring the antigenic experience. In these 3 months of life, the neonate principally depends on components of the innate immune system, $(7,8)$ yet, neonatal innate immune responses may not be fully developed so that the entire performance of its immune system is decreased (9). In premature neonates, the reduced pool of neutrophils and monocytes as well as their precursors lead to greater susceptibility to serious bacterial, viral or fungal infections. A better understanding of the mechanisms underlying neonatal immunity could be helpful in preventing and treating neonatal infections. In this view, Vorbach et al. (10) postulated that the mammary gland has evolved as a protective immune gland as part of the mother's immune system, since human milk is full of various peptides, small proteins, and enzymes with immune activity. Therefore, breastfeeding pro- 
motes immunity through numerous human milk-derived compounds, and among them microRNAs is an important class of emerging biomolecules (11) that play a critical role in gene expression regulation at the post-transcriptional level. This review highlights some of the new concepts associated with human milk miRNAs profiling for the possible control of innate immunity, and discusses their connection with clinical management at the neonatal intensive care unit for preventing neonatal sepsis in critical premature newborns.

\section{Evidence Acquisition}

Titles and abstracts of previous papers were scanned before reading the full-text, in order to retrieve appropriate information. The databases used for the search were PubMed, Cochrane, and Embase for articles published before 1st of July, 2016. Secondary search for articles cited in reference lists was identified by the primary search. The remaining articles were then subject to a citation search before a final hand-search of all reference lists. Papers were deemed eligible if they included the following phrases: "Neonatal premature and sepsis incidence", "innate immunity", "immune modulating microRNAs", "preterm infant and microRNAs", and "human milk and microRNAs". In agreement with our previous papers, all citations were downloaded with the Endnote $₫$ software version 14. To avoid bias of elimination, full text articles were re-considered following the first round exclusions and were subject to two independent eligibility reviews (FL $100 \%$ and LG 20\%), this time with perfect agreement. The studies that were evaluated as adequate were enclosed in the present review.

\section{Results}

\subsection{Neonatal Sepsis}

A serious complication among premature infants with very low birth weight (VLBW) is infectious disease that leads to hospitalization in neonatal intensive care units. Early onset neonatal sepsis (EOS) involves the following risk factors, prematurity, immunologic immaturity, prolonged rupture of membranes, and maternal intraamniotic infection. Although blood culture-proven EOS involves less than $2 \%$ of VLBW premature newborns, it is often associated with considerable morbidity and mortality. What emerges from monitoring EOS is that there is a change in the distribution of pathogens associated with it (2). The predominantly gram-positive infections are switching towards gram-negative organisms. This change is worrying, due to the high death rate associated with gram-negative bacteria. In particular, pathogens causing EOS showed over the past decade, an important decrease of streptococcal Group B infections and a significant increase of Escherichia coli infections. However, Haemophilus influenzae and Listeria monocytogenes may also be identified $(12,13)$. In contrast, gram-positive infections mostly, coagulase negative Staphylococci and Staphylococcus aureus, are characteristic of Late-onset neonatal sepsis (LOS) (14-16). Late-Onset neonatal Sepsis is associated with high mortality due to difficult diagnosis and empirical antibiotic treatment. These are used often inappropriately with an increased risk of both antibiotic resistance and invasive candidiasis infections (14). This latter problem can be overcome by fluconazole prophylaxis in VLBW newborns, during the first 6 weeks of life (17). Today, cost-effective strategies to reduce the burden of LOS are as follows, i) antimicrobial stewardship; ii) limit in steroid use; iii) early enteral feeding; iv) minimization of invasive procedures, and v) hand hygiene.

\subsection{Function of the Innate Immunity}

The immune system consists of cells and molecules with specialized roles in defending the body against invading pathogens. The immune system challenges invading pathogens via 2 different types of responses, which differ from each other regarding the immunologic memory presence. The innate immune responses use natural killer cells and cells belonging to the phagocytic and inflammatory systems, such neutrophils, monocytes, macrophages, basophils, mast cells, and eosinophils. The molecular arm of the innate responses consists of complement, acutephase proteins, and soluble factors, such as cytokines and interferons. The immune system of preterm newborns is immature with a reduced innate and adaptive immunity; in addition, their immune responses may also compromise of other factors due to the preterm birth. In premature newborns, the reduced capability to adequately respond to infections, is mainly related to a) decreased levels of both Immunoglobulins type G (IgGs) and Antimicrobial Proteins and Peptides (APPs); b) impaired function of complement proteins; and c) reduced pool of neutrophils and monocytes. The IgG is transferred to the fetus across the placenta at 32 weeks of gestation (18), so that premature newborns have lower levels of circulating maternal IgGs, which results in a lack of opsonization and impairment of phagocytosis (18). Moreover, APPs released by white blood cells destroy pathogens and are positively correlated with gestational age (19). In premature newborns, the impairment of phagocytosis is amplified by the immaturity of complement proteins of both classical (C1, C4) and alternative (factor B) pathways (20), and by the reduced pool of neutrophils and monocytes and of their precursors, due 
to the low production of granulocyte-macrophage colonystimulating factor (GM-CSF) (19). The decreased synthesis and release of soluble factors also affects cytokines such as interleukin-12 (IL-12) /IL-23, IL-18, and Interferon-gamma $(\mathrm{IFN}-\alpha)$, involved in the efficiency of innate immune response (20).

It has been documented that toll-like receptors (TLRs) play a critical role in early innate immune response (21). These receptors recognize pathogen-associated molecular motifs, and are expressed on the surface of both antigen presenting cells and epithelial cells. The stimulation of TLRs evocates intracellular signaling cascades that in turn lead to transcriptional and cellular activation and cytokine/chemokine production (21). Among TLRs, TLR4 is a transmembrane component of the Lipopolysaccharide (LPS) receptor. It also recognizes heat-shock proteins and unsaturated fatty acids such as lipoteichoic acids synthesized by gram-positive bacteria $(22,23)$.

The LPS, component of E. coli and other gram-negative bacteria, is able to evocate inflammation through its binding to the TLR4/MD2/CD14 complex present on the macrophages surface (24). In preterm infants, the decreased functionality of TLR4 is associated with a reduced receptor expression on cord blood mononuclear cells, supporting the pivotal role of TLR4 in increased susceptibility to infection $(25,26)$. Of note, microRNAs have emerged as fine modulators of TLRs signaling (27), proving to be a bridge between innate and adaptive immune response. MicroRNA in immune regulation is an intense area of research that will facilitate the understanding of the development and the function of the innate immune system in neonates.

\subsection{MicroRNAs Regulation of Innate Immunity}

One of the most promising aspects in modern medicine is undoubtedly the discovery of the family of small non-coding RNAs, known as microRNAs (miRNAs). Originally identified in C. elegans, they were then found in all vertebrates including humans (28) as key regulators of gene expression at post-transcriptional level, either by inhibition of translation or degradation of the mRNA target (29). MiRNAs are found within both the introns or exons of protein-coding regions and the intergenic sites in the genome $(30,31)$. They exist either individually or in clusters $(32,33)$ and they are transcribed from their own genes by RNA Polymerase II (RNA Pol II) to generate single-stranded primary miRNA transcripts (pri-miRNA) in the nucleus (34). Pri-miRNA transcripts are processed by an RNase III ribonuclease, called Drosha, to $\sim 60$ to 70 nucleotides long stem-loop structures known as the precursor of miRNAs (pre-miRNAs) $(35,36)$. The pre-miRNAs are exported out of the nucleus by the Guanosine Triphosphate (Ran-GTP)-dependent Exportin-5 into the cytoplasm $(37,38)$. Within the cytoplasm, further processing of the pre-miRNAs by RNAse III enzyme, known as Dicer, takes place and results in the formation of 18 to 22 nucleotides long miRNA duplexes $(39,40)$. These duplexes are then incorporated into a ribonucleoprotein complex, referred to as RNA-induced silencing complexes (RISC) (41). The RISC complex identifies miRNA targets for translational modulation via complementary base pairing. The RISC complex will cleave the mRNAs if the complementarity between the miRNA and the target mRNA is fulfilled. When the complementarity is partial, as often observed in mammals, the translation process will be inhibited (42). This makes it possible for a single miRNA to bind to many mRNAs and regulate a large number of genes. Most miRNAs are thought to inhibit the translational process by binding to mRNAs at the 3' untranslated region (UTR). However, some reports suggest that miRNAs have also the ability to modulate transcription $(43,44)$. The binding of MiRNAs to the promoter regions of a gene has been shown to either activate or inhibit transcription $(43,44)$. Functional studies indicated that essential cellular processes such as differentiation, apoptosis, and metabolic activities are controlled by varying specific miRNA levels (45). In addition, several authors have demonstrated the essential role of miRNAs in orchestrating immune response (4650). The first miR linked to the immuno system was the miR-155, which is first transferred to the fetus, across the placenta and then the infant later via human milk (Figure 1). It emerges as a central regulator of immunity having an important role in the maturation of macrophages and dendritic cells into the active phenotype through toll-like receptors (TLRs). The regulation of miR-155 expression supports the idea that activating signals are crucial, since danger stimulating signaling via both TLR and interferon, can upregulate miR-155 expression. In fact, upon stimulation with Interferons and Tumor Necrosis Factor (TNF)-alpha, there is an induction of miR-155 in various cell types (51-54). Furthermore, TLR ligands poly (I:C) and LPS acting on TLRs 3 and 4, respectively, induce miR-155 expression in innate cell models (53). The ablation of miR-155 in dendritic cells (DCs) does not induce efficient T-cell activation in response to antigens for the impaired antigen presentation capability (54). A target gene of miR-155 is the suppressor of cytokine signaling 1 (SOCS1) and it is important to mention that SOCS1 per se, negatively regulates the antigen presenting capability of DCs (55). MiR-223 was the first non-coding RNA discovered to be highly expressed in hematopoietic cells of myeloid lineage in both mice and humans (56-58). This microRNA is expressed in cells of the granulocytic lineage acting 
as a differentiation factor. Its expression becomes incrementally higher as granulocytes reach the full mature stage. In contrast, ablation of miR-223 in mice leads to hyper-mature granulocytes, spontaneous inflammatory lung pathology, and cell-autonomous expansion of the granulocyte progenitor population, as one of the miR-223 targets is the transcription factor Mef2c. Myeloid-specific ablation of Mef2c in miR-223 knockout mice rescued the neutrophilia phenotype (56).

The family of the miR-146 is highly expressed in the human monocytic THP-1 cell line upon stimulation by LPS and pro-inflammatory cytokines such as TNF- $\alpha$ or IL-1 $\beta$ (5961). Both miR-146a and miR-146b are transcriptionally upregulated by these molecules, yet, only the miR-146a mature form is generated. This microRNA negatively regulates the acute innate immune response. The miR-146a promoter contains several binding sites for nuclear factor (NF)- $\kappa \mathrm{B}$ and has been shown both in vitro and in vivo to target IRAK1 and TRAF6, thus suppressing the expression of NF- $\kappa$ B's target genes such as IL-6, IL- 8 , IL- $1 \beta$, and TNF- $\alpha$ $(62,63)$. Therefore, miR-146a acts as an effector molecule that drives a negative feedback mechanism, able to attenuate the TLRs response (64). In contrast to miR-155 and miR146 , in macrophages miR-125b is down-regulated upon LPS stimulation (65). Tumor Necrosis Factor- $\alpha$ is also a target gene of miR-125b, suggesting that down-regulation of miR-125b is required to ensure a proper inflammatory response in response to infections by macrophages, or conversely miR-125b may be considered a safety mechanism to ensure negligible TNF- $\alpha$ expression by inadequately stimulated macrophages. The regulation process by microRNAs is shown in Figure 1 and Table 1.

Table 1. Effects of miR146, 155, 223 and 125b on Tumor Necrosis Factor Alpha (TNF $\alpha$ ), Nuclear Factor Kappa-Light-Chain-Enhancer of Activated B Cells (NFkB); Dendritic Cells (DC); Toll-Like Receptor (TLR); Interleukin 6 (IL6) and Interleukin 1 Beta (IL1 $\beta$ )

\begin{tabular}{ll}
\hline miRNA & Regulated Process \\
\hline $\mathbf{1 2 5 b}$ & Control of TNF $\alpha$ production \\
\hline $\mathbf{1 4 6 a}$ & $\begin{array}{l}\text { NFkB-mediated inflammatory response; type 1 interferon } \\
\text { induction and signaling }\end{array}$ \\
\hline $\mathbf{1 5 5}$ & DCs development; maturation granulocytes; monocytes expansion \\
$\mathbf{2 2 3}$ & Monocytes differentiation; granulocytes proliferation/activation; \\
& TLR induction of IL6/IL1 $\beta$ production \\
\hline
\end{tabular}

Abbreviations: DC, Dendritic Cells; IL6, Interleukin 6; IL1 $\beta$, Interleukin 1 beta; NFkB, Nuclear Factor kappa-light-chain-enhancer of activated B cells; TLR, TollLike Receptor; TNF $\alpha$, Tumor Necrosis Factor alpha.

\subsection{Nutrition: The Role of microRNAs}

Vorbach et al. (10) in a previous review, described that mammary gland evolved in a protective immune gland as part of mother's immune system, since human milk is full of various peptide, small proteins, and enzymes with innate immune function. Human breast milk also provides nutrition to the newborn and facilitates the maturation of the newborn's immune system (66). The finding that human breast milk contains microRNAs that tightly regulates innate immunity such as the miR146a opens a new scenario for the biological function of these molecules in neonatal nutrition with a particular focus for premature newborns and VLBW babies. MicroRNAs milk derivatives are stable under harsh conditions such as freeze-thaw cycles and low $\mathrm{pH}$ ( $\mathrm{pH} 1$ ); this is of importance for premature newborns, VLBW, and hospitalized infants, who usually receive freezer-stored breast milk (even donated). Low pH stability suggests that miRNAs can be tolerated by newborn's gastrointestinal milieu and could be absorbed into the small intestine directly influencing the gut mucosal immunity and therefore microbiome $(11,67)$. The analysis of miRNAs profile, in human breast milk, with respect to innate immunity could represent a strategy to treat critical premature newborns. Even if there is a variation between each person, the expression pattern of miRNAs in human breast milk samples of the same mother is constant. Human breast milk reflects a mother's constitution and living environment such as food intake. This aspect assumes an important and crucial meaning for human milk bank since they collect milk form mothers having hospitalized newborns and/or milk from a donor. Identifying a richer human milk batch and using it for critical premature newborns and VLBW disorder could be a tangible way to both improve their health status and reduce the days of hospitalization. The variation in the miRNAs quantity in human milk needs to be considerate. Donor's milk can have different amounts of miRNAs and the identification of a "microMilk" batch richer of miRNAs than others can be a nutrition intervention method for modulating innate immunity in clinical management of premature newborns. Translating this concept for the NICU management of the premature newborn will be a way to protect premature newborns and VLBW by both early and late sepsis.

\section{Conclusions}

Translating the microMilk concept for the NICU routinely, in the management of premature newborns could be a pioneering way for defending premature newborns and VLBW by both early and late sepsis.

\section{Footnote}

Conflict of Interest: GalaScreen srl is an academic spin-off of University of Calabria focusing on microRNAs 


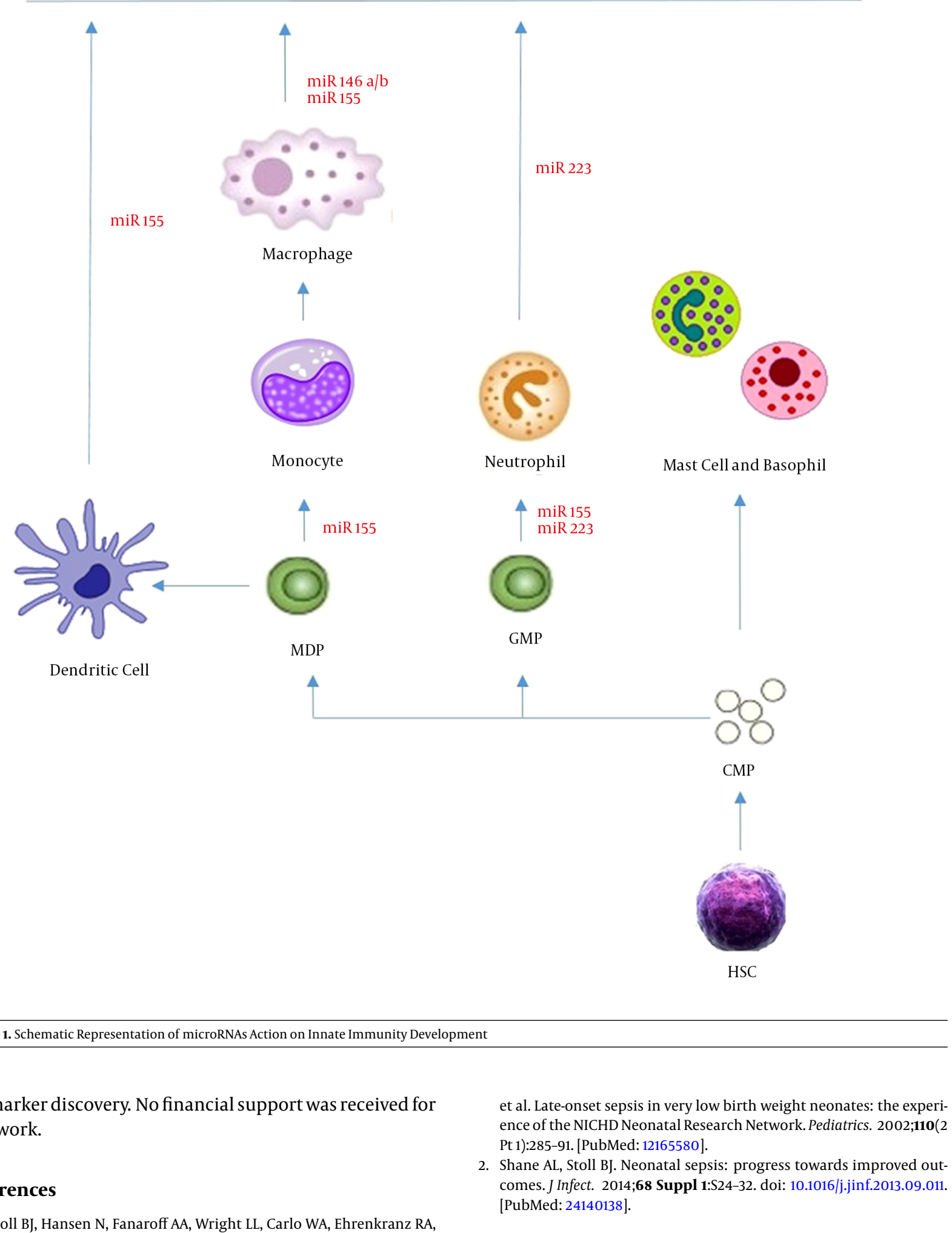

1. Stoll BJ, Hansen N, Fanaroff AA, Wright LL, Carlo WA, Ehrenkranz RA, 
3. Glass HC, Bonifacio SL, Chau V, Glidden D, Poskitt K, Barkovich AJ, et al. Recurrent postnatal infections are associated with progressive white matter injury in premature infants. Pediatrics. 2008;122(2):299-305. doi: 10.1542/peds.2007-2184. [PubMed: 18676547].

4. Adams-Chapman I, Bann CM, Das A, Goldberg RN, Stoll BJ, Walsh MC, et al. Neurodevelopmental outcome of extremely low birth weight infants with Candida infection. J Pediatr. 2013;163(4):961-7 e3. doi: 10.1016/j.jpeds.2013.04.034. [PubMed: 23726546].

5. Adkins B, Leclerc C, Marshall-Clarke S. Neonatal adaptive immunity comes of age. Nat RevImmunol. 2004;4(7):553-64. doi:10.1038/nri1394. [PubMed: 15229474].

6. Clapp DW. Developmental regulation of the immune system. Semin Perinatol. 2006;30(2):69-72. doi: 10.1053/j.semperi.2006.02.004. [PubMed: 16731279].

7. PrabhuDas M, Adkins B, Gans H, King C, Levy O, Ramilo O, et al. Challenges in infant immunity: implications for responses to infection and vaccines. Nat Immunol. 2011;12(3):189-94. doi: 10.1038/ni0311-189. [PubMed: 21321588].

8. Marodi L. Neonatal innate immunity to infectious agents. Infect Immun. 2006;74(4):1999-2006. doi: 10.1128/IAI.74.4.1999-2006.2006. [PubMed: 16552028].

9. Tissieres P, Ochoda A, Dunn-Siegrist I, Drifte G, Morales M, Pfister R, et al. Innate immune deficiency of extremely premature neonates can be reversed by interferon-gamma. PLoS One. 2012;7(3):ee32863. doi: 10.1371/journal.pone.0032863. [PubMed: 22427899].

10. Vorbach C, Capecchi MR, Penninger JM. Evolution of the mammary gland from the innate immune system?. Bioessays. 2006;28(6):60616. doi: 10.1002/bies.20423. [PubMed: 16700061]

11. Kosaka N, Izumi H, Sekine K, Ochiya T. microRNA as a new immuneregulatory agent in breast milk. Silence. 2010;1(1):7. doi: 10.1186/1758907X-1-7. [PubMed: 20226005].

12. Kuzniewicz MW, Walsh EM, Li S, Fischer A, Escobar GJ. Development and Implementation of an Early-Onset Sepsis Calculator to Guide Antibiotic Management in Late Preterm and Term Neonates. Jt Comm J Qual Patient Saf. 2016;42(5):232-9. [PubMed: 27066927].

13. Johnson K, Messier S. Early Onset Sepsis. S D Med. 2016;69(1):29-33. [PubMed: 26882580].

14. Dong Y, Speer CP. Late-onset neonatal sepsis: recent developments. Arch Dis Child Fetal Neonatal Ed. 2015;100(3):F257-63. doi: 10.1136/archdischild-2014-306213. [PubMed: 25425653].

15. Zeng SJ, Tang XS, Zhao WL, Qiu HX, Wang H, Feng ZC. Clinical analysis of cases of neonatal Streptococcus agalactiae sepsis. Genet Mol Res. 2016;15(2) doi: 10.4238/gmr.15027962. [PubMed: 27323190].

16. Bizzarro MJ, Shabanova V, Baltimore RS, Dembry LM, Ehrenkranz RA, Gallagher PG. Neonatal sepsis 2004-2013: the rise and fall of coagulase-negative staphylococci. J Pediatr. 2015;166(5):1193-9. doi: 10.1016/j.jpeds.2015.02.009. [PubMed: 25919728].

17. Kaufman DA, Morris A, Gurka MJ, Kapik B, Hetherington S. Fluconazole prophylaxis in preterm infants: a multicenter case-controlled analysis of efficacy and safety. Early Hum Dev. 2014;90 Suppl 1:S87-90. doi: 10.1016/S0378-3782(14)70026-X. [PubMed: 24709470].

18. Palmeira P, Quinello C, Silveira-Lessa AL, Zago CA, Carneiro-Sampaio M. IgG placental transfer in healthy and pathological pregnancies. Clin Dev Immunol. 2012;2012:985646. doi: 10.1155/2012/985646. [PubMed: 22235228].

19. Strunk T, Currie A, Richmond P, Simmer K, Burgner D. Innate immunity in human newborn infants: prematurity means more than immaturity. J Matern Fetal Neonatal Med. 2011;24(1):25-31. doi: 10.3109/14767058.2010.482605. [PubMed: 20569168].

20. Zhu J, Paul WE. CD4 T cells: fates, functions, and faults. Blood. 2008;112(5):1557-69. doi: 10.1182/blood-2008-05-078154. [PubMed: 18725574].

21. Kawai T, Akira S. Toll-like receptors and their crosstalk with other innate receptors in infection and immunity. Immunity. 2011;34(5):63750. doi: 10.1016/j.immuni.2011.05.006. [PubMed: 21616434].

22. Kim JY, Kim H, Jung BJ, Kim NR, Park JE, Chung DK. Lipoteichoic acid isolated from Lactobacillus plantarum suppresses LPS-mediated atherosclerotic plaque inflammation. Mol Cells. 2013;35(2):115-24. doi: 10.1007/s10059-013-2190-3. [PubMed: 23456333].

23. Kimbrell MR, Warshakoon H, Cromer JR, Malladi S, Hood JD, Balakrishna $\mathrm{R}$, et al. Comparison of the immunostimulatory and proinflammatory activities of candidate Gram-positive endotoxins, lipoteichoic acid, peptidoglycan, and lipopeptides, in murine and human cells. Immunol Lett. 2008;118(2):132-41. doi: 10.1016/j.imlet.2008.03.009. [PubMed: 18468694].

24. Forster-Waldl E, Sadeghi K, Tamandl D, Gerhold B, Hallwirth U, Rohrmeister K, et al. Monocyte toll-like receptor 4 expression and LPSinduced cytokine production increase during gestational aging. Pediatr Res. 2005;58(1):121-4. doi: 10.1203/01.PDR.0000163397.53466.0F. [PubMed: 15879290].

25. Sharma AA, Jen R, Brant R, Ladd M, Huang Q, Skoll A, et al. Hierarchical maturation of innate immune defences in very preterm neonates. Neonatology. 2014;106(1):1-9. doi: 10.1159/000358550. [PubMed: 24603545].

26. Sampath V, Mulrooney NP, Garland JS, He J, Patel AL, Cohen JD, et al. Toll-like receptor genetic variants are associated with Gramnegative infections in VLBW infants. J Perinatol. 2013;33(10):772-7. doi 10.1038/jp.2013.80. [PubMed: 23867959].

27. Xu G, Zhang Z, Xing Y, Wei J, Ge Z, Liu X, et al. MicroRNA149 negatively regulates TLR-triggered inflammatory response in macrophages by targeting MyD88. J Cell Biochem. 2014;115(5):919-27. doi: 10.1002/jcb.24734. [PubMed: 24375488]

28. Landgraf P, Rusu M, Sheridan R, Sewer A, Iovino N, Aravin A, et al. A mammalian microRNA expression atlas based on small RNA library sequencing. Cell. 2007;129(7):1401-14. doi: 10.1016/j.cell.2007.04.040. [PubMed: 17604727].

29. Friedman RC, Farh KK, Burge CB, Bartel DP. Most mammalian mRNAs are conserved targets of microRNAs. Genome Res. 2009;19(1):92-105. doi: 10.1101/gr.082701.108. [PubMed: 18955434].

30. Lagos-Quintana M, Rauhut R, Lendeckel W, Tuschl T. Identification of novel genes coding for small expressed RNAs. Science. 2001;294(5543):853-8. doi: 10.1126/science.1064921. [PubMed: $11679670]$.

31. Lau NC, Lim LP, Weinstein EG, Bartel DP. An abundant class of tiny RNAs with probable regulatory roles in Caenorhabditis elegans. Science. 2001;294(5543):858-62. doi: 10.1126/science.1065062. [PubMed 11679671].

32. Bartel DP. MicroRNAs: genomics, biogenesis, mechanism, and function. Cell. 2004;116(2):281-97. [PubMed: 14744438].

33. Kim VN, Nam JW. Genomics of microRNA. Trends Genet 2006;22(3):165-73. doi:10.1016/j.tig.2006.01.003. [PubMed: 16446010].

34. Lee Y, Kim M, Han J, Yeom KH, Lee S, Baek SH, et al. MicroRNA genes are transcribed by RNA polymerase II. EMBO J. 2004;23(20):4051-60. doi: 10.1038/sj.emboj.7600385. [PubMed: 15372072].

35. Denli AM, Tops BB, Plasterk RH, Ketting RF, Hannon GJ. Processing of primary microRNAs by the Microprocessor complex. Nature. 2004;432(7014):231-5. doi: 10.1038/nature03049. [PubMed: 15531879].

36. Han J, Lee Y, Yeom KH, Kim YK, Jin H, Kim VN. The Drosha-DGCR8 complex in primary microRNA processing. Genes Dev. 2004;18(24):301627. doi: 10.1101/gad.1262504. [PubMed: 15574589].

37. Yi R, Qin Y, Macara IG, Cullen BR. Exportin-5 mediates the nuclear export of pre-microRNAs and short hairpin RNAs. Genes Dev. 2003;17(24):3011-6. doi:10.1101/gad.1158803. [PubMed:14681208].

38. Lund E, Guttinger S, Calado A, Dahlberg JE, Kutay U. Nuclear export of microRNA precursors. Science. 2004;303(5654):95-8. doi: 10.1126/science.1090599. [PubMed: 14631048].

39. Hutvagner G, McLachlan J, Pasquinelli AE, Balint E, Tuschl T, Zamore PD. A cellular function for the RNA-interference enzyme Dicer in the maturation of the let-7 small temporal RNA. Science. 2001;293(5531):834-8. doi: 10.1126/science.1062961. [PubMed 11452083]. 
40. Ketting RF, Fischer SE, Bernstein E, Sijen T, Hannon GJ, Plasterk RH. Dicer functions in RNA interference and in synthesis of small RNA involved in developmental timing in C. elegans. Genes Dev. 2001;15(20):2654-9. doi: 10.1101/gad.927801. [PubMed: 11641272].

41. Gregory RI, Chendrimada TP, Cooch N, Shiekhattar R. Human RISC couples microRNA biogenesis and posttranscriptional gene silencing. Cell. 2005;123(4):631-40. doi: 10.1016/j.cell.2005.10.022. [PubMed: 16271387].

42. Valencia-Sanchez MA, Liu J, Hannon GJ, Parker R. Control of translation and mRNA degradation by miRNAs and siRNAs. Genes Dev. 2006;20(5):515-24. doi: 10.1101/gad.1399806. [PubMed: 16510870].

43. Janowski BA, Younger ST, Hardy DB, Ram R, Huffman KE, Corey DR. Activating gene expression in mammalian cells with promoter-targeted duplex RNAs. Nat Chem Biol. 2007;3(3):166-73. doi: 10.1038/nchembio860. [PubMed: 17259978].

44. Place RF, Li LC, Pookot D, Noonan EJ, Dahiya R. MicroRNA-373 induces expression of genes with complementary promoter sequences. Proc Natl Acad Sci U S A. 2008;105(5):1608-13. doi:10.1073/pnas.0707594105. [PubMed: 18227514].

45. Stefani G, Slack FJ. Small non-coding RNAs in animal development NatRev Mol Cell Biol. 2008;9(3):219-30. doi:10.1038/nrm2347. [PubMed: 18270516].

46. Guedes J, Cardoso AL, Pedroso de Lima MC. Involvement of microRNA in microglia-mediated immune response. Clin Dev Immunol. 2013;2013:186872. doi: 10.1155/2013/186872. [PubMed: 23762086].

47. Luo X, Ranade K, Talker R, Jallal B, Shen N, Yao Y. microRNA-mediated regulation of innate immune response in rheumatic diseases. Arthritis Res Ther. 2013;15(2):210. doi: 10.1186/ar4194. [PubMed: 23582400].

48. Spinelli SV, Diaz A, D’Attilio L, Marchesini MM, Bogue C, Bay ML, et al. Altered microRNA expression levels in mononuclear cells of patients with pulmonary and pleural tuberculosis and their relation with components of the immune response. Mol Immunol. 2013;53(3):2659. doi:10.1016/j.molimm.2012.08.008. [PubMed: 22964481].

49. Curtale G, Citarella F, Carissimi C, Goldoni M, Carucci N, Fulci V, et al. An emerging player in the adaptive immune response: microRNA$146 \mathrm{a}$ is a modulator of IL-2 expression and activation-induced cell death in T lymphocytes. Blood. 2010;115(2):265-73. doi: 10.1182/blood2009-06-225987. [PubMed: 19965651].

50. Du LL, Ma ZF. [MicroRNA and immune response, and sepsis]. Zhongguo Wei Zhong Bing Ji Jiu Yi Xue. 2009;21(8):501-3. [PubMed: 19695178].

51. O'Connell RM, Taganov KD, Boldin MP, Cheng G, Baltimore D. MicroRNA-155 is induced during the macrophage inflammatory response. Proc Natl Acad Sci U S A. 2007;104(5):1604-9. doi: 10.1073/pnas.0610731104. [PubMed: 17242365].

52. Imaizumi T, Tanaka H, Tajima A, Yokono Y, Matsumiya T, Yoshida H, et al. IFN-gamma and TNF-alpha synergistically induce microRNA155 which regulates TAB2/IP-10 expression in human mesangial cells. Am J Nephrol. 2010;32(5):462-8. doi: 10.1159/000321365. [PubMed: 20948191].

53. O'Connell RM, Chaudhuri AA, Rao DS, Baltimore D. Inositol phosphatase SHIP1 is a primary target of miR-155. Proc Natl Acad Sci U S A. 2009;106(17):7113-8. doi: 10.1073/pnas.0902636106. [PubMed: 19359473].
54. Moffett HF, Novina CD. A small RNA makes a Bic difference. Genome Biol. 2007;8(7):221. doi:10.1186/gb-2007-8-7-221. [PubMed:17666120].

55. Ceppi M, Pereira PM, Dunand-Sauthier I, Barras E, Reith W, Santos MA, et al. MicroRNA-155 modulates the interleukin-1 signaling pathway in activated human monocyte-derived dendritic cells. Proc Natl Acad Sci U S A. 2009;106(8):2735-40. doi: 10.1073/pnas.0811073106. [PubMed: 19193853].

56. Johnnidis JB, Harris MH, Wheeler RT, Stehling-Sun S, Lam MH, Kirak $\mathrm{O}$, et al. Regulation of progenitor cell proliferation and granulocyte function by microRNA-223. Nature. 2008;451(7182):1125-9. doi: 10.1038/nature06607. [PubMed: 18278031].

57. Fazi F, Rosa A, Fatica A, Gelmetti V, De Marchis ML, Nervi C, et al. A minicircuitry comprised of microRNA-223 and transcription factors NFI-A and C/EBPalpha regulates human granulopoiesis. Cell. 2005;123(5):819-31. doi: 10.1016/j.cell.2005.09.023. [PubMed: 16325577].

58. Haneklaus M, Gerlic M, O'Neill LA, Masters SL. miR-223: infection, inflammation and cancer. J Intern Med. 2013;274(3):215-26. doi: 10.1111/joim.12099. [PubMed: 23772809].

59. Pauley KM, Satoh M, Chan AL, Bubb MR, Reeves WH, Chan EK. Upregulated miR-146a expression in peripheral blood mononuclear cells from rheumatoid arthritis patients. Arthritis Res Ther. 2008;10(4):R101. doi: 10.1186/ar2493. [PubMed: 18759964].

60. Tang Y, Luo X, Cui H, Ni X, Yuan M, Guo Y, et al. MicroRNA-146A contributes to abnormal activation of the type I interferon pathway in human lupus by targeting the key signaling proteins. Arthritis Rheum. 2009;60(4):1065-75. doi:10.1002/art.24436. [PubMed: 19333922].

61. Williams AE, Perry MM, Moschos SA, Larner-Svensson HM, Lindsay MA. Role of miRNA-146a in the regulation of the innate immune response and cancer. Biochem Soc Trans. 2008;36(Pt 6):1211-5. doi: 10.1042/BST0361211. [PubMed: 19021527].

62. Hou J, Wang P, Lin L, Liu X, Ma F, An H, et al. MicroRNA-146a feedback inhibits RIG-I-dependent Type I IFN production in macrophages by targeting TRAF6, IRAK1, and IRAK2.JImmunol. 2009;183(3):2150-8. doi: 10.4049/jimmunol.0900707. [PubMed: 19596990].

63. Nahid MA, Pauley KM, Satoh M, Chan EK. miR-146a is critical for endotoxin-induced tolerance: IMPLICATION IN INNATE IMMUNITY. J Biol Chem. 2009;284(50):34590-9. doi: 10.1074/jbc.M109.056317. [PubMed: 19840932].

64. Li L, Chen XP, Li YJ. MicroRNA-146a and human disease. Scand J Immunol. 2010;71(4):227-31. doi: 10.1111/j.1365-3083.2010.02383.x. [PubMed: 20384865].

65. Tili E, Michaille JJ, Cimino A, Costinean S, Dumitru CD, Adair $\mathrm{B}$, et al. Modulation of miR-155 and miR-125b levels following lipopolysaccharide/TNF-alpha stimulation and their possible roles in regulating the response to endotoxin shock. J Immunol. 2007;179(8):5082-9. [PubMed: 17911593].

66. Goldman AS. The immune system in human milk and the developing infant. Breastfeed Med. 2007;2(4):195-204. doi: 10.1089/bfm.2007.0024. [PubMed: 18081456].

67. Zhou Q, Li M, Wang X, Li Q, Wang T, Zhu Q, et al. Immune-related microRNAs are abundant in breast milk exosomes. Int J Biol Sci. 2012;8(1):118-23. [PubMed: 22211110]. 